DEPARTMENT OF

ECONOMICS

\title{
Using contests to allocate pollution rights
}

\author{
Ian A. MacKenzie
}

Nick Hanley

Tatiana Kornienko

Stirling Economics Discussion Paper 2008-21

October 2008

Online at http://www.economics.stir.ac.uk 


\title{
Using contests to allocate pollution rights
}

\author{
Ian A. MacKenzie ${ }^{a, *}$, Nick Hanley ${ }^{b}$ and Tatiana Kornienko ${ }^{c}$ \\ ${ }^{a}$ Center for Economic Research, ETH Zürich, 8092 Zürich, Switzerland \\ ${ }^{b}$ Department of Economics, University of Stirling, Stirling UK FK9 4LA \\ ${ }^{c}$ Department of Economics, University of Edinburgh, Edinburgh EH8 9JY, UK
}

\begin{abstract}
In this paper we advocate a new initial allocation mechanism for a tradable pollution permit market. We outline a Permit Allocation Contest (PAC) that distributes permits to firms based on their rank relative to other firms. This ranking is achieved by ordering firms based on an observable 'external action' where the external action is an activity or characteristic of the firm that is independent of their choice of emissions in the tradeable permit market. We argue that this mechanism has a number of benefits over auctioning and grandfathering. Using this mechanism efficiently distributes permits, allows for the attainment of a secondary policy objective and has the potential to be more politically appealing than existing alternatives.

Keywords: Rank-order contests; pollution permits; initial allocation JEL Classification: D44; Q25
\end{abstract}

\footnotetext{
${ }^{*}$ Corresponding author: E-mail: imackenzie@ethz.ch (I. MacKenzie). Tel: +41 4463224 27; Fax:+41 446321362 .
} 


\section{Introduction}

The key feature of tradeable permit markets is that, in theory, they allow society to achieve a given reduction in pollution at the lowest costs to the economy. Under ideal conditions, how permits are initially allocated amongst polluting firms will not effect this cost-efficiency property. This has led many to view decisions over how to initially allocate permits as being mainly decisions about fairness, rather than efficiency. Dating back to Hahn (1984) and Stavins (1995), economists have pointed to ways in which initial allocations can matter for cost efficiency, and this has led to an active debate investigating the optimal choice of initial allocation mechanisms. This debate takes on much greater relevance given the current expansion of tradeable permit schemes worldwide, such as Phase Two of the EU-ETS, and the Regional Greenhouse Gas Initiative and Western Climate Initiative schemes in the US. The two alternatives for initial allocation which most have considered are grandfathering (a free allocation of permits based on historical emissions or outputs), and the auctioning of permits (Goulder 1995; Parry 1995; Parry et al. 1999; Cramton and Kerr 2002; Requate 2005). Grandfathering occurs when the regulator freely allocates allowances to each firm based on their historical emissions (or perhaps output or some other proxy). Although a popular and frequently used mechanism, grandfathering is far from an ideal allocation mechanism as it is often viewed as politically cumbersome and inefficient (Stavins 1998; Cramton and Kerr 2002). Firms may have an incentive to lobby the regulator in favour of larger permit allocations which, due to the use of wasteful resources, may reduce social welfare in the economy. Moreover, when grandfathering is used with information that is updated over time - updated grandfathering - a link is created between a firm's current level of emissions and it's future permit allocation which may result in a distortionary incentive to increase emissions (Böhringer and Lange 2005; MacKenzie et al. 2008). In this case, grandfathering no longer produces a cost-efficient level of abatement on the 
part of firms. This is because firms know that they can influence the amount of permits they are allocated in a future period through their permit holdings during the current period.

The main alternative to grandfathering is generally considered to be auctioning. In an auction, permits are allocated to each firm based on their monetary bid relative to every other firm (Lyon 1982; Hahn and Noll 1982; Oehmke 1987; Franciosi et al. 1993; Cramton and Kerr 2002). Auctions are often considered to be a 'lump-sum' allocation mechanism as permits are distributed to each firm independent of their historical emissions, thus removing one of the problems arising in updated grandfathering schemes. Due to this characteristic, auctioning is viewed as a desirable and efficient method of allocating permits (Cramton and Kerr 2002). However, the main drawback, and as a result, the main reason for the infrequent use of auctions is the political difficulty in implementing such a mechanism. As the winners in the auction are obliged to pay for their permits, firms' resistance against implementing auctions have been a severe restriction on the implementation of such schemes. The financial burden of pollution control to firms under an auction may be as great as under an emissions tax (Hanley, Shogren and White, 2007). ${ }^{1}$

It is possible to reduce firms' resistance to auctions by redistributing permit auction revenues to the participants (a revenue-neutral auction (Hahn and Noll (1982)) or to reduce distortionary taxes elsewhere in the economy (the revenue recycling effect (Parry 1995; Parry et al. 1999)). However, such schemes are very rarely implemented, and may therefore attract little credibility with lobbyists when auction schemes are proposed (Goulder,1995; Pezzy and Park, 1998). With problems associated with both grandfathering and auctioning it is therefore desirable to try and find alternative mechanisms

\footnotetext{
${ }^{1}$ Auctioning, however, is slowly becoming an increasingly important and favoured initial allocation mechanism in existing tradeable permit markets, such as the US SOE 'Acid Rain' Program and the European Union Emissions Trading Scheme (EU-ETS).
} 
for the initial allocation of tradeable permits. Indeed, the literature has rarely considered the use of alternative allocation mechanisms beyond grandfathering and auctions. The aim of this paper to broaden the discussion of allocation mechanisms by outlining an alternative allocation mechanism that may be preferred to existing approaches.

Our proposed alternative mechanism, a Permit Allocation Contest (PAC), distributes permits to firms based on their rank relative to each other. The ranking is achieved by ordering firms based on an observable 'external action' where the external action is an activity or characteristic of the firm that is independent of their choice of emissions in the tradeable permit market. This ranking criterion is determined by the regulator who chooses this to meet a secondary policy objective. We argue that this mechanism has a number of additional benefits over traditional allocation schemes. Similar to auctions, a PAC will efficiently allocate permits in the tradable permit market. However, it can simultaneously achieve a secondary policy objective, such as the reduction in noise pollution or improvement in corporate and social responsibility targets. Given the wide variety of possible ranking criteria and secondary policy objectives available, the PAC may also be easier to implement in the face of intense interest group pressure than an auction.

The remainder of our paper is organised as follows: Section 2 discusses the allocation mechanism and the possible benefits of implementing such as scheme. Section 3 discusses the regulator's optimal choice of permit distribution in the PAC, while Section 4 illustrates the potential implementation of the mechanism in the European Emissions Trading Scheme and Section 5 concludes. 


\section{A Permit Allocation Contest}

To understand how a Permit Allocation Contest has the potential to work in a tradable permit market, it is beneficial to consider the different possible types of contest that exist. Two main mechanisms exist: rank-order tournaments and rank-order contests. The distinction between the two rests on the relationship between agents' unobservable effort and observable actions. Rank-order tournaments are incentive schemes used in situations where firms' performance is observed with some exogenous noise. That is, in rank-order tournaments, it is generally assumed that each agent experiences a stochastic relationship between their effort and actions. For example, in the control of non-point source pollution, an agent's efforts could be in the form of land management changes. The regulator cannot observe these efforts, but instead measures the effects of this effort on water quality. However, stochastic processes determine the relationship between the

farmer's effort, and the consequent impacts on water quality, making it difficult for the regulator to infer what the farmer has or has not done. When the observation noise is common to all firms, rank-order tournaments typically outperform absolute, or individualistic, schemes (Lazear and Rosen 1981; Holmström 1982; Green and Stokey 1983; Nalebuff and Stiglitz 1983; Mookherjee 1984).

When there is no individual-specific noise involved in the observation of firms' actions, one can implement a rank-order contest, which is, in effect, a multi-prize allpay auction (Glazer and Hassin 1988; Barut and Kovenock 1998; Clark and Riis 1998; Moldovanu and Sela 2001; 2006). This differs from tournaments as agents in rank-order contest models are generally assumed to have a deterministic relationship between effort and actions. In a rank-order contest, there is a finite number of prizes to be distributed among the participating agents, with the size of each prize known before the onset of the contest. Firms compete in this contest by submitting costly (monetary or nonmonetary) "bids". Firms then are ranked in order of their bids, and the "prizes" are 
distributed to the firms according to firms' rankings. That is, a firm that submits the highest bid is ranked first, and thus gets the largest permit allocation ("first prize"), the firm that submits the second-highest bid is ranked second, and thus gets second-largest allocation ("second prize"), and so on, up to the firm that submits the lowest bid being ranked last, and thus receiving the smallest allocation (possibly nothing). Rank-order contests, like tournaments, tend to outperform alternative types of individualistic and contract based regulation.

In this paper we discuss the implementation of a rank-order contest. A similar argument can also be applied to rank-order tournaments. Our rank-order contest, the Permit Allocation Contest, attempts to reach a middle ground between grandfathering and auctioning as an initial allocation mechanism. As our model is a type of multiunit 'all-pay auction' it has many similarities to a standard permit auction. Yet, as the ranking criterion in the PAC can be non-monetary, it can share certain desirable characteristics with a grandfathering mechanism.

\subsection{The allocation mechanism}

Consider a competitive tradable permit market with $n$ participating firms. Within this market each firm has the option either to purchase permits from the market or to abate pollution. However, each firm must hold enough permits to cover their emissions. The regulator has responsibility of initially allocating permits to the participating firms. Aside from regulating emissions in a tradable permit market, let us assume the regulator also has a secondary (unrelated) objective where the regulator aims to minimise a social 'bad' produced by all firms in the permit market. This secondary objective could relate to the improvement of health and safety incidents, reductions in noise pollution, cuts in other pollutants not related to the permit market, or encouraging corporate social responsibility. Therefore, in our model, the regulator aims to minimise the aggregate 
social 'bad' (or maximise some social 'benefit') by using incentives in the form of permit allocations (without the need for standard command and control regulation). This turns out to provide an attractive way of allocating permits.

The regulator is assumed to have two non-competing policy objectives. Firstly, the regulator is motivated to choose a schedule of permit allocations to minimise the aggregate abatement cost in the tradeable permit market-the standard permit market regulatory objective. Second, the additional objective of the regulator is to provide incentives for the permit market firms to achieve some predetermined public policy target linked to the external actions of firms which we define as the maximisation of expected aggregate external actions. As such, the regulator is assumed to adopt economic efficiency as its sole criterion: whilst it wishes a cost-effective solution to the pollution control problem which the permit market addresses, it seeks the biggest improvement in its secondary objective (say, health and safety at work). For present purposes, it will be sufficient to assume that the marginal benefits of this secondary objective are always bigger than the marginal costs; or that the secondary objective is deemed to be desirable on other grounds (eg ethical or political).

To keep the argument as general as possible, we assume that firms will be ranked on their choice of an observable 'external action'. External actions are those which allow the regulator to meet its secondary objective. To adhere to the regulator's public policy objective, firm $i$ chooses an external 'action' (such as reductions in noise pollution) denoted by $z_{i}$, in which it bears a cost $v\left(z_{i}\right)$. The external action can be, at the extreme, an invariant characteristic of a firm, e.g. population for a country under a global tradeable permit market. However, it is most likely that an external factor will be chosen so that firms have the ability to alter their permit allocation. The observable 'external action' is an activity or characteristic of the firm which is independent from its choice of emissions and the permit market. The regulator aims to select an appropriate 
criterion to rank all firms so that the action is independent of emission choices and where the aggregate action can fulfil an objective set by the regulator. ${ }^{2}$

In order for firms to obtain a permit allocation, the regulator chooses an ordered schedule (vector) of permit allocations, $\mathbf{s}=\left(s_{1}, s_{2}, \ldots, s_{n}\right) \in \mathbb{R}_{+}^{n}$ subject to $s_{1} \geq s_{2} \geq$ $\ldots \geq s_{n} \geq 0$ and $\sum_{j=1}^{n} s_{j}=E$ where $s_{j}$ is the $j^{t h}$ permit allocation and $E$ is the absolute aggregate emissions cap for the tradeable permit market (the regulator's precise choice of permit allocations will be considered later in this paper). Using this permit allocation schedule, the regulator distributes a (possibly unequal) permit allocation to each firm whilst ensuring the absolute emissions cap is binding. The specific permit allocation to a firm depends on each firm's size of external action relative to every other firm, so that firms that have a larger relative size of external action obtain a larger permit allocation. $^{3}$

In a PAC, the regulator observes the external actions of all firms and ranks them in descending order of their external action where the firm with the highest level of external action is ranked first, the second highest firm is ranked second and so on until all firms are ranked. Each ranked-ordered firm obtains a corresponding permit allocation so that the firm with the top ranking obtains the largest permit allocation $\left(s_{1}\right)$, the second ranked obtains the second highest permit allocation $\left(s_{2}\right)$ and so on until all individual permit allocations are distributed to the firms.

\footnotetext{
${ }^{2}$ In most permit markets, the participation of firms in the permit market is usually dependent on their inclusion in a product market e.g. a permit market may require participation of all energy producers. Given the permit market participants have similar product markets, it is possible that each firm in the permit market has a number of characteristics or 'actions' that are comparable amongst all participants, independently chosen from its emissions and socially beneficial, which can be used as the external factor.

${ }^{3}$ The regulator must choose an external action that is feasible for the tradeable permit market. participating firms. In addition, if the industry exhibits increasing returns to scale, a regulator could allocate permits based on how each firm's present external action compares to its own past external action - e.g. based on the percentage reduction of noise pollution over time. However, scale effects will be captured by the form of the cost function described later. To avoid size effects, it is likely the regulator could use changes in external action throughout time, for example, the relative reduction of noise pollution over time.
} 
Firms are assumed to have different abilities at producing their external action (ie different costs). In particular, each firm privately knows their ability parameter before the PAC commences. Although each firm knows its own ability parameter and the distribution of ability parameters for its competitors, no firm knows the actual realization of its rivals' ability parameters. The regulator is assumed to also know the distribution of abilities, but not the individual ability level of each firm. Similarly, although the permit allocation schedule is common knowledge, each firm's actual permit allocation is uncertain at the time of the decision-making. In other words, by participating in PAC, all firms engage in a game of incomplete information. Given its knowledge of own ability, of the distribution of abilities, and of schedule of permit allocations, each firm uses its expectations of permit allocation to choose an optimal level of external action.

Firms' optimal external actions are determined by a number of factors. First, the shape (or curvature) of the cost function $v(\cdot)$ is an important determinant of the level of external action chosen by each firm. Indeed, the 'less' convex a firm's cost function, the higher the optimal external action. Second, a higher market equilibrium permit price would lead to each firm choosing a higher external action. Third, a general increase in the regulator's schedule of permit allocations would increase the value of the marginal permit allocation, thus increasing the optimal external action. This might result from a fall in the number of firms who will be allocated permits. Furthermore, an increase in the number of firms, as well as certain changes in the distribution of abilities may also lead to higher optimal external actions.

\section{$3 \quad$ What's good about a Permit Allocation Contest?}

Having outlined the nature of the PAC, we now review some of the advantages of this approach to permit allocation, relative to auctions or grandfathering. The potential of 
rank-based mechanisms has been pointed out by few authors. By applying the seminal work of Lazear and Rosen (1981), Govindasamy et al. (1994) advocated the use of a tournament to control non-point pollution, whereby each polluting firm is ranked by its input use or pollution abatement effort. Govindasamy et al. (1994) found that a tournament can work well as it can achieve the same efficiency conditions as a Pigouvian tax but with less costly information requirements. Shogren and Hurley (1997) experimentally tested a tournament reward system to consider the implication for environmental

policy (for example, they considered Coasian bargaining and environmental conflict) and found that using such a reward system made the experiment participants behave in a similar manner to theoretical predictions (for example, the Coasian bargaining outcome was achieved). They showed that tournaments reached the theoretical outcomes quicker than other "standard" mechanisms which suggests tournaments systems can provide robust incentives to effectively implement environmental regulation

\subsection{Stronger incentives to invest in actions to reduce other "bads"}

In a PAC, the decisions regarding the number and size of permit allocations has a substantially different effect on the incentives of each firm compared to alternative mechanisms, such as a 'winner-pays' auction. The permit allocations in a PAC are not directly related to the firms' external actions, but instead they are determined by firms' rankings according to the size of their external actions. Thus, a small increase in the firm's external actions may result in a disproportionately large change in permit allocation. For example, a small increase in external action by the second-ranked firm could make this firm the winner of the contest, and thus lead to the largest permit 
allocation (which is typically made to be substantially larger than the "second prize").

Moreover, as Krishna and Morgan (1997) showed, all-pay auctions tend to generate higher aggregate bids than their winner-pay counterparts, that is, traditional permit auctions. In addition, as Moldovanu and Sela (2001) showed, when the prize structure is suitably chosen, such a contest will tend to generate the largest aggregate bids (in our case, the largest improvement in the secondary objective). As the choice of external action at the margin can significantly alter a firm's permit allocation, the robust incentives created in the PAC system should induce all firms to maximise their external action.

\subsection{Flexible options for the regulator in improve policy ac- ceptability}

As the ranking criterion need not be monetary in value, a wide variety of possible external actions can exist (any action that is independent of emissions choices is admissible). It follows that one may be chosen so that the pollution permit scheme is more politically acceptable for the regulator, market participants and the wider economy. Consequently, a PAC system has the possibility of being implemented in a wide variety of tradeable permit market contexts. For instance, a PAC could be implemented in an international permit market where the participating countries are allocated permits (or a burden is assigned to each country) based on their (country) external actions, such as the proportion of recycling in each country. The system could also be adapted to smaller markets, such as firms choosing external actions based on their improvement in noise pollution. Every tradeable permit market has heterogeneous circumstances in which it operates and with a PAC, public policy objectives (and external actions)

\footnotetext{
${ }^{4}$ This frequently happens in sport tournaments where the difference between prizes (and notably between first and second prizes) is non-linearly increasing (Szymanski 2003).
} 
can be chosen to compliment the social 'norms' and prevailing political opinion in the specific emissions trading scheme. In contrast, although auctioning and grandfathering can be used in all tradeable permit markets, the only allocation criterion available is the comparison of firms' money 'bids' and historical emissions, respectively. The lack of other possible allocation criterion may make implementation more difficult.

\subsection{Political benefits}

Using a PAC in a tradeable permit market offers the political benefit of having a clear connection between permit allocations (including the differences between them) and some socially beneficial firm action. This avoids one criticism of grandfathering, namely that it results in polluters being rewarded with valuable permits for their previous polluting actions: heavy polluters typically being awarded more permits at the start of the market than smaller polluters. It is possible that a PAC system may actually appear fairer to a number of groups in society than alternative mechanisms as it couples permit allocation (a reward to the firms) with some public policy objective. In contrast, grandfathering permits creates a perverse link between emissions and the value of permits each firm receives. ${ }^{5}$

Similar to the auctioning of permits, a PAC takes an 'instrumentalist' perspective in that it ignores past and current permit holdings when determining permit allocations (Raymond 2003). Therefore, this type of allocation approach treats all firms equally in that firms who invest early in pollution abatement are not implicitly punished (as would happen under a grandfathering scheme). However, unlike an auction, a PAC mechanism can be adapted so non-monetary criterion are used to rank the firms which

\footnotetext{
${ }^{5}$ The equitable issues associated with permit allocation are notoriously under researched in economics, mainly due to the normative aspects involved (Raymond 2003). All allocation mechanisms can appear 'fair' as it very much depends on the attitude to property and the specific circumstances, i.e. an industry level or global emissions trading scheme.
} 
may be more appealing to participating firms than an auction. For example, a nonmonetary criterion may be chosen which is closer to the production and/or managerial decisions of firms.

\subsection{The existence of an appropriate external factor}

Although a PAC distribution mechanism has a number of possible advantages over alternative mechanisms, a limitation of a PAC is that the external action must be defined in an appropriate manner. As noted above, an optimal external action has to be independent of emissions so that no distortions are created in the permit market whilst simultaneously being politically acceptable and observable to the regulator. The ease with which an external action can be chosen crucially depends on the specific institutional context of the permit market. For instance, when the market participants are countries such as in an international permit market, it may be relatively easy to

find an external action that is both socially beneficial and independent of emissions. Countries in a carbon dioxide permit market, such as the EU-ETS, could be ranked on the proportional reduction of landfill waste from the non-trading sector (or the production of methane from it), or on some social goal such as reductions in road traffic accidents, or the percentage of firms signing up to Corporate Social Responsibility agreements.

\section{The regulator's optimal choice of allocations}

In a PAC, the regulator has the ability to allocate permits based on a criterion that it chooses. We now look into how the regulator can maximize the aggregate external actions to achieve its secondary objective by choosing an appropriate permit allocation schedule; and at how this relates to the subsequent operation of the tradeable permit 
market.

As Glazer and Hassin (1988) and Barut and Kovenock (1998) showed, have proved to maximise the aggregate external action, the lowest-ranked permit allocation $s_{n}$ must involve zero permits. If this did not occur, otherwise, there would be an incentive for firms with 'weaker' abilities to reduce their level of external action and obtain a positive level of permit allocation. Choosing a vector of permit allocations with $s_{n}=0$ will induce each firm to choose a non-zero level of external action. In essence, have $(n-1)$ non-zero permit allocations. If the firm who is ranked last still expects to receive a permit allocation, no matter how small, then this produces an incentive to take no action.

Some general insights to the problem were provided by Moldovanu and Sela (2001; 2006) and references therein, advocating for some discriminatory features of contests. In particular, Moldovanu and Sela (2001) showed that when costs functions are linear or concave, it is optimal to allocate the prize "pie" to only a single "first" prize. They also showed when cost functions are convex, several positive prizes may be optimal.

As is known in the theoretical literature, only the "allocation distance" between neighbouring-ranked permit allocations $s_{j-1}-s_{j}$ is important for firms' incentives. That is, what is important is how much more permits a $j$-th ranked firm could have obtained from moving one rank up to rank $j-1$, rather than the absolute levels of permit allocations $s_{j}$ and $s_{j-1}$. Thus, one of the important questions to be addressed is whether an optimal allocation schedule involves consequently ranked allocations which are equal to each other. To see this, let us think what happens when an allocation $s_{j}$ increases. For $2 \geq j \geq n-1$, any unit increase in an allocation $s_{j}$ has two effects. First, as $s_{j}$ increases, this decreases the "upward distance" $s_{j-1}-s_{j}$, and thus has a negative "upward distance" effect. Second, as $s_{j}$ increases, the "downward distance" $s_{j}-s_{j+1}$ increases, so that the "downward distance" effect is positive. Given this we 
can immediately see that $s_{1}$, the first permit allocation, has only positive marginal effects. That is, $s_{1}$ only has a "downward distance" effect which means increasing the first allocation will result in aggregate external actions increasing. In contrast, the last permit allocation $s_{n}$ only has a negative "upward distance" effect, which means increasing the lowest allocation will result in a reduction in aggregate external actions. As the marginal effect of $s_{n}$ is negative, this is sufficient to require that the bottomranked allocation $s_{n}$ is equal to zero.

For a tradable permit market with $n$ firms, a regulator would maximise a secondary objective whilst efficiently allocating permits to the market if only $(n-1)$ permit allocations were distributed This would incentivise low ability firms to select a positive level of external actions, as noted above. Given the allocations are uncertain at the point of deciding a level of allocation, all firms will participate as their expected value of permit allocation is significantly large. Note this expected values has the ability of being altered by the regulator's selection of permit allocations. As the lowest ranked firm obtains no permits from the contest, the firm will, as in a normal competitive market, abate pollution up to the point at which their marginal abatement cost is equated to the permit price.

One popular permit allocation schedule discussed in tradeable permit market literature involves an egalitarian distribution of permits across all firms or countries (Raymond 2003). For example, allocating an equal number of permits per capita has been strongly advocated as a distributional rule for an international permit market (Kverndokk 1995; Rose et al. 1998). While some form of egalitarian allocation may have a number of merits, it may not be desirable to achieve the second policy objective. To see this, consider an extreme egalitarian allocation where firms obtain identical number of permits independent of all firms' actions or characteristics - a 'pure' lump-sum approach, i.e. $s_{1}=s_{2}=\cdots=s_{j-1}=s_{j}=\cdots=s_{n}$ (in other words, all "allocation 
distances" are zero). In such a scenario, the regulator's schedule of permit allocations is $\mathbf{s}^{\text {egal }}=\left(\frac{E}{n}, \frac{E}{n}, \ldots, \frac{E}{n}\right)$, where each firm in the PAC obtains an identical share of the aggregate emissions cap. This means that the distribution of permits is independent of each firm's choice of external action, and that no incentive exists for firms to choose a positive level of external action. In policy terms, this type of egalitarian approach should not be chosen if the regulator wants to combine the permit allocation of a tradeable permit market with a public policy objective. For a regulator to succeed in a public policy objective, it must instead choose a schedule of permit allocations that discriminates in favour of firms with larger external actions and against the ones with smaller actions.

\subsection{Example: the case of four firms}

We consider a simple case, assuming a uniform distribution of firms' abilities with support $\left[\frac{1}{2}, 1\right]$. Recall that the bottom-ranked permit allocation $s_{n}$ is set equal to zero. As Figure 1a shows, the marginal effect of the top allocation $s_{1}$ is the highest for the lowest-cost firms. On the other hand, the marginal effect of the second-ranked allocation $s_{2}$ peaks out for the mid-range costs, and the effect for the third-ranked allocation $s_{3}$ peaks out for the relatively higher-cost firms, and, moreover, the heights of the peaks are similar. This, together with the convexity of costs, suggests a possibility that it might be optimal to set the third-ranked allocation $s_{3}$ equal to the second-ranked allocation $s_{2}$.

Indeed, let us first check what happens if we set the third-ranked allocation $s_{3}$ equal to zero. Setting $s_{3}=0$ allows us to express the middle allocation as $s_{2}=E-s_{1}$, with $s_{1} \in\left[\frac{E}{3}, E\right]$. In this case, as Figure 1b suggests, the expected aggregate external action

has a maximum around $s_{1} \approx \frac{E}{2}$. In other words, here it is not optimal to allocate the entire "pie" of permit allocations only to a single top-ranked firm, i.e. we need that 


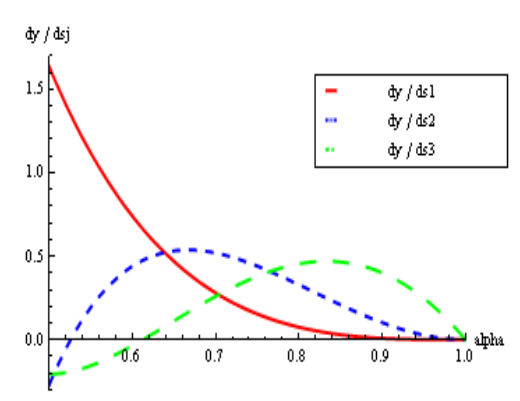

a)

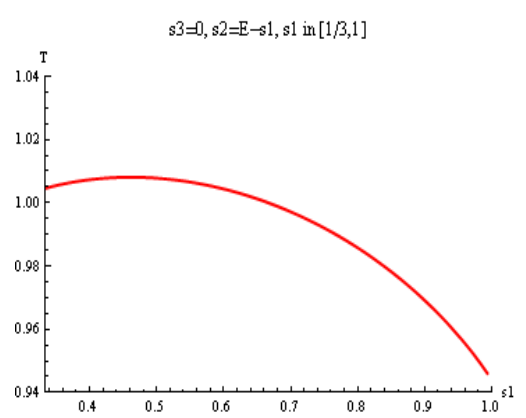

b)

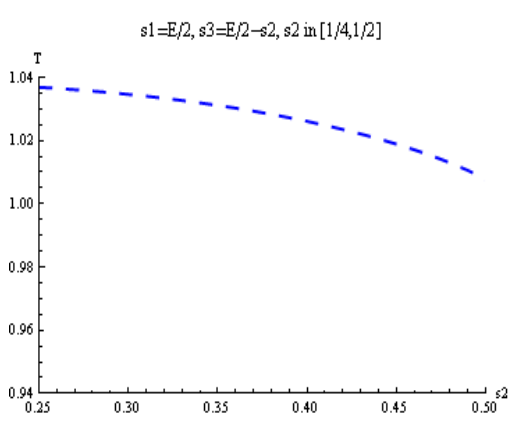

c)

Figure 1: Case of $n=4, \alpha_{i} \sim U\left[\frac{1}{2}, 1\right]:$ a) the total marginal effects of allocations $s_{1}, s_{2}$, and $s_{3}$ (the solid red curve, the narrowly dashed blue curve, and the widely dashed green curve, respectively), as a function of the cost parameter $\alpha_{i}$; b) the aggregate external action $T$ as a function of the top-ranked allocation $s_{1}$ for $s_{3}=0, s_{2}=E-s_{1}$; c) the aggregate external action $T$ as a function of the second-ranked allocation $s_{2}$ for $s_{1}=\frac{E}{2}$, $s_{3}=\frac{E}{2}-s_{2}($ for $E=1, p=1, v(\cdot)=\sqrt{\cdot})$.

$s_{1}<E$. Furthermore, if we now set the top-ranked allocation equal to a half of the pie (so that $s_{3}=\frac{E}{2}-s_{2}$ ), the Figure 1c confirms that it would be optimal to set the third-ranked allocation to be equal to the second-ranked allocation, i.e. $s_{2}=s_{3}$. Thus, the optimal allocation schedule for four firms and costs distributed uniformly on $\left[\frac{1}{2}, 1\right]$, will be approximately equal to $s_{1} \approx \frac{E}{2}, s_{2} \approx s_{3} \approx \frac{E}{4}, s_{4}=0$.

Performing similar manipulations for costs distributed uniformly on $[1,5]$, we find that the optimal allocation schedule for four firms will be approximately equal to $s_{1} \approx$ $\frac{4 E}{5}, s_{2} \approx s_{3} \approx \frac{E}{10}, s_{4}=0$ (see Figure 2$)$.

Similarly, we found that for other uniform distributions, the pattern is similar, i.e. the highest expected aggregate external action happens when there is a relatively large top allocation, followed by two equal allocations, with the bottom allocation being zero. For example, for $\alpha_{i} \sim U\left[\frac{1}{3}, 1\right]$, we have that $s_{1} \approx \frac{3 E}{5}, s_{2} \approx s_{3} \approx \frac{E}{5}, s_{4}=0$; for $U[1,2]$ - $s_{1} \approx \frac{E}{2}, s_{2} \approx s_{3} \approx \frac{E}{4}, s_{4}=0 ; U[1,10]-s_{1} \approx \frac{9 E}{10}, s_{2} \approx s_{3} \approx \frac{E}{20}, s_{4}=0$. While our numerical findings may not be robust with respect to the shape of the distribution 


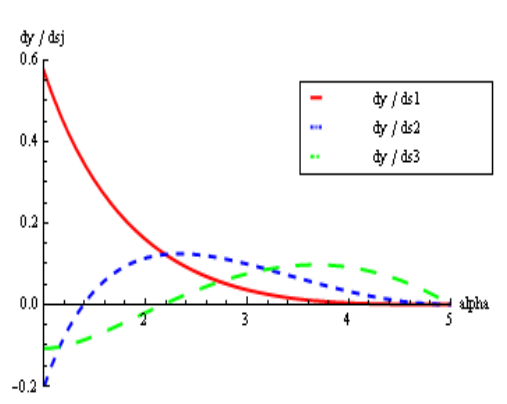

a)

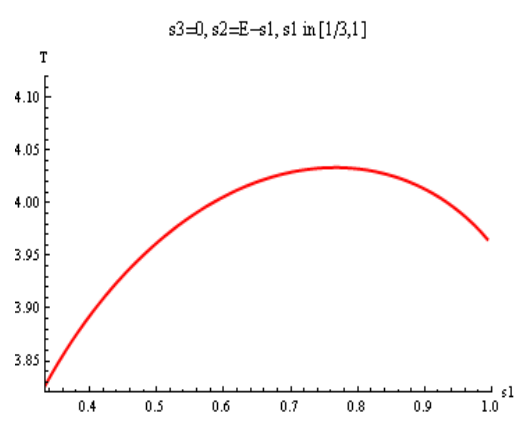

b)

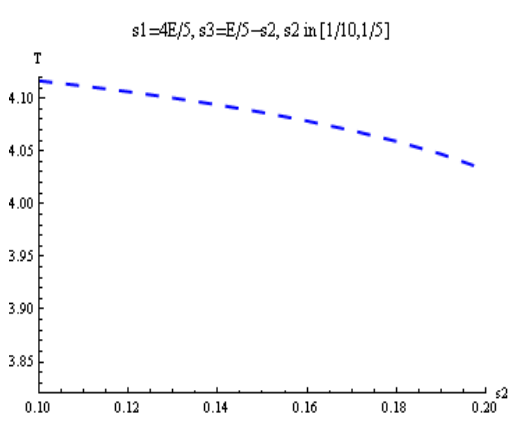

c)

Figure 2: Case of $n=4, \alpha_{i} \sim U[1,5]$ : a) the total marginal effects of allocations $s_{1}, s_{2}$, and $s_{3}$ (the solid red curve, the narrowly dashed blue curve, and the widely dashed green curve, respectively), as a function of the cost parameter $\alpha_{i}$; b) the aggregate external action $T$ as a function of the top-ranked allocation $s_{1}$ for $s_{3}=0, s_{2}=E-s_{1}$; c) the aggregate external action $T$ as a function of the second-ranked allocation $s_{2}$ for $s_{1}=\frac{4 E}{5}, s_{3}=\frac{E}{5}-s_{2}($ for $E=1, p=1, v(\cdot)=\sqrt{\cdot})$.

and the number of firms, we are however able to show, similarly to Moldovanu and Sela (2001), that the optimal allocation schedule in the presence of convex costs need not be very discriminatory, possibly exhibiting equal consecutively-ranked allocations. However, our work also suggests a possibility that the optimal allocation schedules will tend to involve the top allocation $s_{1}$ to be larger than the lower-ranked allocations.

This case is instructive, as it shows some important features of contests. Here, in order to "lift off" the external action by the relatively high-cost firms, the regulator may need to award a positive middle allocation. However, at the margin, the middle allocation is less effective for the relatively low-cost firms. Thus, if the realized sample of firms' costs parameters consists only of relatively high cost parameters, the ex-post optimal schedule involves equal top and middle allocations. If, instead, the realized sample of firms' costs parameters consists only of relatively low cost parameters, the ex-post optimal schedule involves only a single top allocation. However, since here the cost parameters are firms' private information, one needs to look into the ex-ante 
regulator's problem, i.e. to look into the expected total external actions.

\section{Potential applications to the EU-ETS.}

To illustrate the many possible applications of the PAC permit allocation mechanism, we discuss the possible consequences for implementing in the EU Emissions Trading Scheme (EU-ETS). The EU-ETS was the first emissions trading scheme in the world to set compulsory $\mathrm{CO}_{2}$ targets. Commencing in 2005 with phase periods 2005-2007 and 2008-2012, aggregate emissions of participating (trading) sectors such as energy, cement, glass paper and pulp, were capped. This resulted in nearly 12,000 installations being regulated which produced $46 \%$ of the total $\mathrm{EU} \mathrm{CO}_{2}$ emissions (Watanabe and Robinson, 2005). To implement a PAC, we discuss two possible scenarios where (i) firms participate in the PAC to obtain permit allocation and (ii) members states participate in a PAC to obtain a level of overall aggregate emissions.

Consider a PAC where the participants are firms within the EU-ETS. Let us first assume that the PAC is decentralised to each member state. Within a PAC, the participating firms would be ranked in order of their external action. For the EU-ETS, the external action may be chosen by each member states to achieve a secondary policy objective which is entirely focused on Member States' preferences. For example, corporate and social responsibility may be a requirement. This may be politically appealing for Member states with unique policy requirements. Allowing the decentralisation of the PAC may have the potential to cause strategic behaviour in the choice of a secondary policy objective. For instance, a Member State may choose a relatively "easy" secondary objective, where their firms have relatively low cost in completing an action and hence reduce the cost of obtaining permits. However, the PAC can deal with this issue by ranking firms such that the absolute level of external actions no longer mat- 
ters. Another possibility is for the PAC to be centralised within the EU-ETS. In such a case, the European Commission selects the external action and secondary public policy. This may be beneficial due to the prevention of strategic behaviour by Member states. Moreover, the European Commission can focus on a specific requirement that it values as important for all firms in the EU-ETS, for example, the reduction in noise pollution, or the improvement of health and safety at work. By allowing firms to participate in a PAC, many possible secondary benefits can be produced, whilst avoiding the problems of grandfathering and auctions. However, it may be difficult to select an external action as not all firms may share sufficient characteristics in terms of the secondary objective.

One other possibility is to allow Member states to participate in the PAC. Currently, the Kyoto Protocol allows regional economic regions, such as the EU, to legitimately act, sign and ratify the convention (and any future protocols) on a EU scale whilst using internal procedures to differentiate targets amongst the member states (United Nations, 1992). In other words, the EU was allowed to create a 'bubble' where the burden of a common EU target could be redistributed between member states - commonly known as the Burden Sharing Agreement (BSA) (Phylipsen et al., 1998; Ringius, 1999; European Commission, 2000; Lacasta et al., 2002; European Union, 2003). After significantly costly and drawn-out political discussions an agreement was reached in 1998 where European carbon dioxide emissions would, in net, reduce by 8 per cent of 1990 levels. An alternative to the BSA is to introduce a PAC to determine the carbon dioxide reduction burden each member state has to bear. The European Commission could outline a contest in which lower burdens of carbon dioxide reduction are awarded to higher-ranked member states in a PAC. Ranking member states on some criterion would be relatively simple. For example, ranking could be based on member states' nonpermit trading sectors improvements in pollution from domestic transport, pollution from landfills, recycling, and so on. So long as the criterion avoids correlations between 
actions and carbon dioxide abatement activities in the permit market, then the PAC is an efficient allocation mechanism. Additionally, the Europe Commission can focus on inducing Member States to comply with other EU regulations e.g. reduction in landfill waste, water quality and so on. Instead of allocation being based purely on political factors, allowing the PAC to distribute abatement burdens rewards Member States who have successfully produced actions that benefit the European Commission's other public policy objectives.

\section{Conclusions}

The objective of this paper was to outline a new type of permit allocation mechanism. In our model, the initial allocation of tradeable pollution permits is done via a Permit Allocation Contest (PAC). A PAC is a rank-order contest in which the firms are allocated permits according to the ordinal rank of the size of their external action. This is an activity or characteristic of the participating firms that is independent of emissions choices, and which contributes towards achieving a secondary social objective.

In our model, the regulator was assumed to have two policy objectives. First, by allocating permits based on the external action (rather than based on emissions), the regulator aims to minimise the aggregate cost of reducing emissions through avoiding interference with the least-cost potential of a tradeable permit market. Second, by choosing a suitable permit allocation schedule (i.e. the number of permits that firms can obtain by being ranked first, second, and so on), the regulator aims to fulfil a secondary public policy objective, requiring maximisation of the aggregate actions, such as improvements in health and safety policies, corporate and social responsibility or noise pollution. Since, by construction, the permit allocation schedule is independent of emissions, the allocation mechanism results in cost-effective permit market, in contrast 
to the outcome under updated grandfathering. Moreover, the PAC avoids the issues of rewarding firms for past emissions (associated with grandfathering), whilst allowing for the regulator to avoid the financial burdens which a conventional permit auction would impose on industry.

We considered an incomplete information game of PAC, where the permit allocation schedule as well as the cost distribution are publicly known, but where each firm's cost parameter of external actions is the firm's private information. To obtain the public policy objective, the regulator must choose an optimal permit allocation schedule. We find that an egalitarian allocation schedule (whereby firms obtain identical permit allocations regardless of their external action) cannot achieve the public policy objective as an egalitarian allocation schedule leads to zero aggregate external actions. Instead, for the secondary public policy objective to be achieved, the schedule must be discriminatory - at least for the lower-ranked permit allocations. Our numerical analysis is in accordance with these theoretical results. It shows that for the maximum aggregate external actions to be obtained, the lowest-ranked permit allocation has to be zero, and, when costs of external actions are convex, the higher-ranked permit allocations have to be less discriminatory. This paper provides guidance for policymakers on how to implement a PAC and select an optimal permit allocation schedule for a public policy objective. In particular, we have shown that the regulator's optimal permit allocation schedule will depend extensively on the structure and distribution of firms' costs, which must be taken into consideration when implementing a PAC.

A PAC, at its simplest, has attempted to reach the middle ground between grandfathering and auctioning. On one hand, a PAC creates similar incentives to an auction and could, in theory, efficiently allocate permits. On the other hand, it has features of grandfathering as it does not require politically unpopular monetary bids, and thus reduces the financial burden of regulation to industry. While a PAC does require other 
forms of expenditure, a suitably designed PAC may require expenditure on sociallybeneficial activities which firms are already pursuing even in the absence of a PAC, or which firms may find to attractive to pursue. Thus, a suitable designed PAC may be both politically feasible and efficient. In addition, a PAC is a flexible mechanism as it allows ranking of firms using a wide variety of external actions, and thus could be adapted to a variety of industrial and regional circumstances. Moreover, a PAC involves a clear rule of prize allocation (i.e. no regulator's subjective judgement is involved), and are easily adaptable to changing market and technological conditions.

One possible practical difficulty of implementation of a PAC lies in the identification and implementation of a suitable external action. This is because in order for the PAC to achieve efficiency, the external action must be independent of emissions, and in addition it has to be politically agreeable to firms, the regulator and politicians. It might be difficult to identify an external action that satisfies all these requirements. However, we hope that further research will help to overcome these identification and implementation problems.

\section{Acknowledgements}

The authors would like to thank David Bell, Ed Hopkins and Matti Liski for useful comments and suggestions. The usual disclaimer applies.

\section{References}

Barut, Y., Kovenock, D., 1998. The symmetric multiple prize all-pay auction with complete information. European Journal of Political Economy, 14 (4), 627-644. 
Böhringer, C., Lange, A., 2005. On the design of optimal grandfathering schemes for emission allowances. European Economic Review, 49 (8), 2041-2055.

Clark, D.J., Riis, C., 1998. Influence and the discretionary allocation of several prizes. European Journal of Political Economy, 14 (4), 605-625.

Cramton, P., Kerr, S., 2002. Tradeable carbon permit auctions: How and why to auction not grandfather. Energy Policy, 30 (4), 333-345.

Franciosi, R. Isaac, M., Pingry, D., Reynolds, S., 1993. An experimental investigation of the Hahn-Noll revenue neutral auction for emissions licenses. Journal Environmental Economic Management, 24 (1), 1-24.

Glazer, A., Hassin, R., 1988. Optimal contests. Economic Inquiry, 26 (1), 133-143.

Goulder,L.H., 1995. Environmental taxation and the 'double dividend': a reader's guide. International Tax and Public Finance, 2 (2), 157-183.

Govindasamy, R., Herriges, J.A., Shogren, J.F. (1994). Nonpoint tournaments, in: Tomasi,T., Dosi, C., (Eds.), Nonpoint-Source Pollution Regulation: Issues and Analysis, Kluwer Academic Publishers, pp. 87-105.

Green, J.R., Stokey, N.L., 1983. A comparison of tournaments and contracts. Journal of Political Economy, 91 (3), 349-364.

Hahn, R.W., 1984. Market power and transferable property rights. Quarterly Journal of Economics, 99 (4), 753-765.

Hahn, R., Noll, R., 1982. Designing a market for tradeable emissions permits, in: Magat, W.A. (Ed.), Reform of Environmental Regulation,Cambridge, Massachusetts, pp. 119146. 
Holmström, B., 1982. Moral hazard in teams. Bell Journal of Economics, 13 (2), 324340.

Krishna, V., Morgan, J., 1997. An analysis of the war of attrition and the all-pay auction. Journal of Economic Theory, 72 (2), 343-362.

Kverndokk, S. 1995. Tradeable $\mathrm{CO}_{2}$ emission permits: initial distribution as a justice problem. Environmental Values 4, 129-148.

Lazear, E.P., Rosen, S. (1981). Rank order tournaments as optimum labor contracts, Journal Political Economy, 89 (5), 841-864.

Lyon, R.M. 1982. Auctions and alternative procedures for allocating pollution rights. Land Economics, 58 (1), 16-32.

MacKenzie, I.A., Hanley, N., Kornienko, T. 2008. The optimal initial allocation of pollution permits: a relative performance approach. Environmental and Resource Economics, 39 (3), 265-282.

Moldovanu, B., Sela, A. 2001. The optimal allocation of prizes in contests. American Economic Review, 91 (3), 542-558.

Moldovanu, B., Sela, A., 2006. Contest architecture. Journal of Economic Theory, 126 (1), 70-96.

Montgomery, D. 1972. Markets in licenses and efficient pollution control programs. Journal of Economic Theory, 5 (3), 395-418.

Mookherjee, D. 1984. Optimal incentive schemes with many agents. Review of Economic Studies, 51 (3), 433-446.

Nalebuff, B.J., Stiglitz, J.E. 1983. Prizes and incentives: towards a general theory of compensation and competition. Bell Journal of Economics, 14 (1), 21-43. 
Oehmke, J., 1987. The allocation of pollutant discharge permits by competitive auction. Resources and Energy 9 (2), 153-162.

Parry, I., 1995. Pollution taxes and revenue recycling. Journal of Environmental Economics and Management, 29 (3), S-64-S-77.

Parry, I., Williams, R.C., Goulder, L., 1999. When can carbon abatement policies increase welfare? The fundamental role of distorted factor markets. Journal of Environmental Economics and Management, 37 (1), 52-84.

Raymond, L., 2003. Private rights in public resources, Resources for the Future, RFF Press, Washington D.C..

Requate, T., 2005. Dynamic incentives by environmental policy instruments- a survey. Ecological Economics, 54 (2-3),175-195.

Pezzy, J.V., Park, A., 1998. Reflections on the double dividend debate. Environmental and Resource Economics, 11 (3-4), 539-555.

Rose, A., Stevens, B., Edmonds, J. and Wise, M. (1998). International equity and differentiation in global warming policy. Environmental and Resource Economics 12 (1), 25-51.

Shogren, J.F., Hurley, T.M. 1997. Tournament incentives in environmental policy, in: Dragon, A., Jacobsson, K. (Eds.), Sustainability and global environmental policy, Edward Elgar, Cheltenham UK, pp. 213-231.

Stavins, R.N., 1995. Transaction costs and tradable permits. Journal of Environmental Economics and Management, 29 (2), 133-148.

Stavins, R.N., 1998. What can we Learn from the grand policy experiment? Lessons from $\mathrm{SO}_{2}$ Allowance Trading. Journal of Economic Perspectives, 12 (3), 9-88. 
Szymanski, S., 2003. The economic design of sporting contests. Journal of Economic Litareture, 41 (4), 1137-1187.

Watanabe, R., Robinson, G., 2005. The European Union Emissions Trading Scheme (EU-ETS.). Climate Policy, 5 (1), 10-14. 